\title{
HIERARCHICALLY INTELLIGENT MACHINES
}


This page is intentionally left blank 


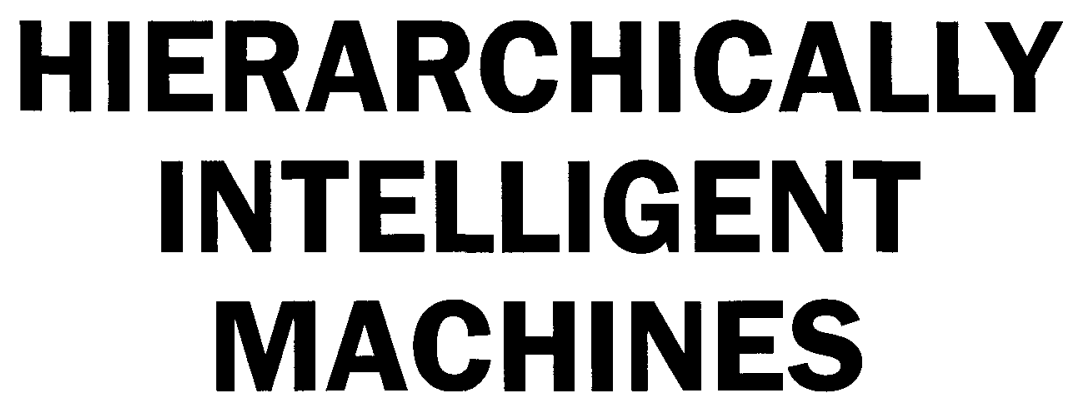

\section{George N Saridis}

Rensselaer Polytechnic Institute, USA 


\section{Published by}

World Scientific Publishing Co. Pte. Ltd.

P O Box 128, Farrer Road, Singapore 912805

USA office: Suite 1B, 1060 Main Street, River Edge, NJ 07661

UK office: 57 Shelton Street, Covent Garden, London WC2H 9HE

\section{British Library Cataloguing-in-Publication Data}

A catalogue record for this book is available from the British Library.

\section{HIERARCHICALLY INTELLIGENT MACHINES}

Copyright 12001 by World Scientific Publishing Co. Pte. Ltd.

All rights reserved. This book, or parts thereof, may not be reproduced in any form or by any means, electronic or mechanical, including photocopying, recording or any information storage and retrieval system now known or to be invented, without written permission from the Publisher.

For photocopying of material in this volume, please pay a copying fee through the Copyright Clearance Center, Inc., 222 Rosewood Drive, Danvers, MA 01923, USA. In this case permission to photocopy is not required from the publisher.

ISBN $981-02-4790-7$

Printed in Singapore by Uto-Print 
To my father Nicholas 
This page is intentionally left blank 


\section{TABLE OF CONTENTS}

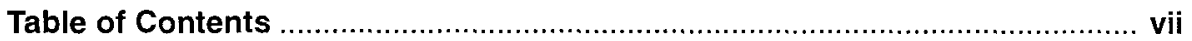

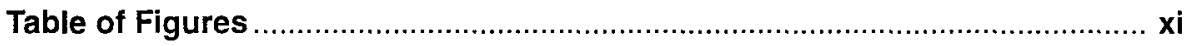

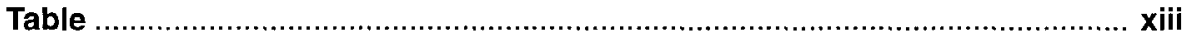

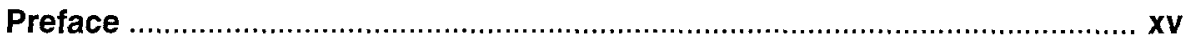

Chapter 1.

\section{INTRODUCTION}

11 MOTIVATION

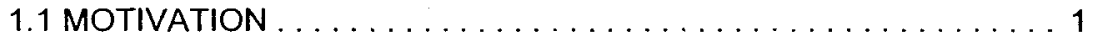

1.2. AUTOMATION AND CONTROL IN MODERN SOCIETY . . . . . 4

1.3 INTELLIGENT MACHINES-A SURVEY

1.4 BOOK ORGANIZATION ................... 11

1.5 REMARKS ........................... 11

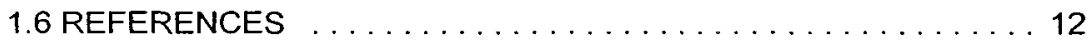

Chapter 2.

MACHINE INTELLIGENCE, KNOWLEDGE AND PRECISION; CONCEPTS AND DEFINITIONS

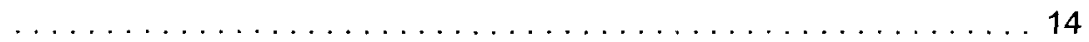

2.1 INTRODUCTION ....................... 14

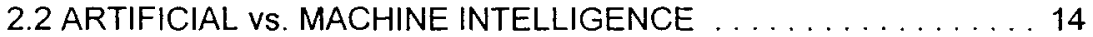

2.3 SMART SYSTEMS .................... 17

2.4 KNOWLEDGE AND INTELLIGENCE IN THE MACHINE . . . . 17

2.5 PRECISION AND COMPLEXITY . . . . . . . . . . . 21

2.6 HIERARCHICALLY INTELLIGENT CONTROL . . . . . . . 21

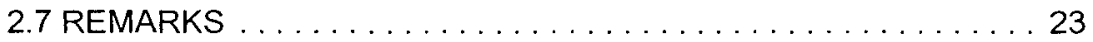

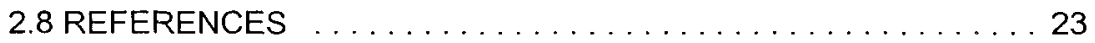

Chapter 3.

ENTROPY AND THE PRINCIPLE OF INCREASING PRECISION WITH DECREASING INTELLIGENCE (IPDI)

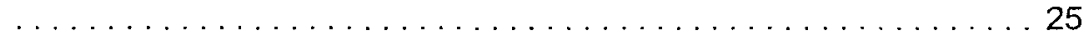

3.1 UNCERTAINTY AND ENTROPY $\ldots \ldots \ldots \ldots \ldots \ldots \ldots \ldots 25$ 
-viiiHIERARCHICALLY INTELLIGENT CONTROL

3.2 ENTROPY AND THERMODYNAMICS: BOLTZMANN . . . . 26 3.3 ENTROPY AND INFORMATION THEORY: SHANNON $\ldots \ldots \ldots .28$ 3.4 KOLMOGOROV'S $\varepsilon$-ENTROPY . . . . . . . . . . . 28

3.5 ENTROPY, ENVIRONMENT AND MANUFACTURING . . . . . 28

3.6 THE MODIFIED JAYNES' PRINCIPLE OF MAXIMUM ENTROPY . 29

3.7 THE PRINCIPLE OF INCREASING PRECISION DECREASING

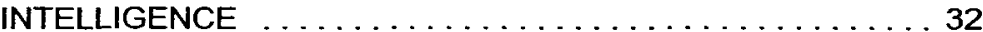

3.8 REMARKS . . . . . . . . . . . . . . . . . 33

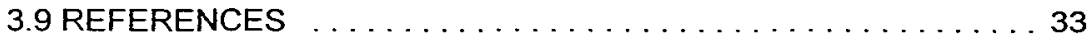

\section{Chapter 4.}

\section{THE ANALYTIC FORMULATION OF HIERARCHICALLY INTELLIGENT MACHINES}

4.1 INTRODUCTION . . . . . . . . . . . . . . . . . . 37

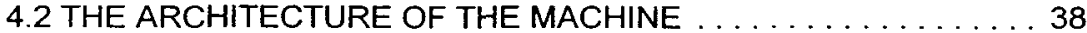

4.3 DEFINITIONS OF THE PROCEDURE ............. 38

4.4 HIERARCHICAL MODELING OF THE LEVELS OF THE

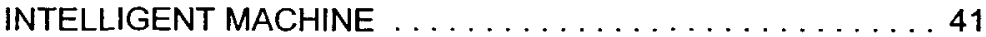

4.5 REMARKS .......................... 42

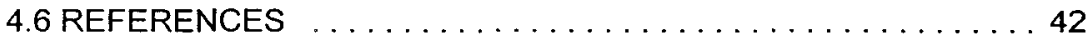

Chapter 5.

HIERARCHICALLY INTELLIGENT CONTROL: THE ORGANIZATION LEVEL 45

5.1 INTRODUCTION 45

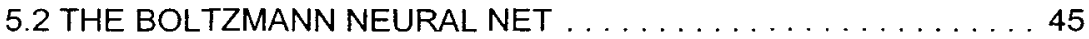

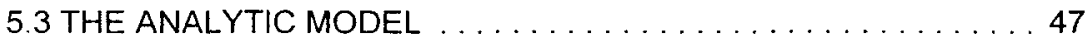

5.4 SEARCH TECHNIQUES . . . . . . . . . . . . . . 50

5.4.1 Simulated Annealing Algorithm. . . . . . . . . . 52

5.4.2 Expanding Subinterval Random Search Algorithm .... 52

5.4 .3 Genetic Search Algorithm ................. 53

5.4.4 Modified Global Genetic Algorithm . . . . . . . . . 54

5.4.5 A Test Case for Comparisons ... . . . . . . . . . . 54

5.5 REMARKS . . . . . . . . . . . . . . . . . . 55

5.6 REFERENCES ....................... 59

Chapter 6.

HIERARCHICALLY INTELLIGENT CONTROL: THE COORDINATION LEVEL 
6.1 INTRODUCTION

6.2 THE ARCHITECTURE OF COORDINATION ... . . . . . . 61

6.3 PETRI NETS AND PETRI NET TRANSDUCERS . . . . . . . . . 63

6.4 THE COORDINATION STRUCTURE . . . . . . . . . . 66

6.5 TASK SCHEDULING AND TRANSLATION . . . . . . . . . . 71

6.6 PERFORMANCE AND ENTROPY . . . . . . . . . . . 71

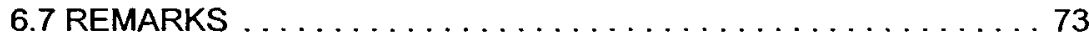

6.8 REFERENCES $\ldots \ldots \ldots \ldots \ldots \ldots \ldots \ldots \ldots \ldots \ldots \ldots$

\section{Chapter 7.}

HIERARCHICALLY INTELLIGENT CONTROL: THE EXECUTION LEVEL

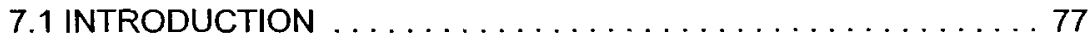

7.2 THE THEORY OF GLOBAL ENTROPY $\ldots \ldots \ldots \ldots \ldots \ldots . \ldots 78$

7.3 ENTROPY FORMULATION OF MOTION CONTROL . . . . . . . . . 79

7.4 ENTROPY MEASURES OF STEREO VISION SYSTEMS . . . . . 80

7.5 REMARKS .......................... 82

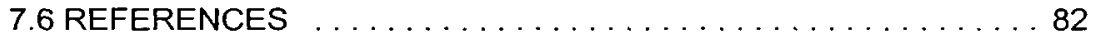

Chapter 8.

\section{HIERARCHICALLY INTELLIGENT CONTROL: APPLICATION TO ROBOTIC SYSTEMS}

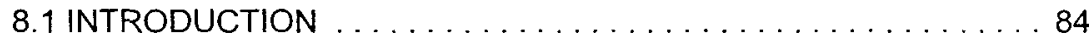

8.2 THE ARCHITECTURE OF THE ORGANIZATION LEVEL . . . . . 84

8.3 THE ARCHITECTURE OF THE COORDINATION LEVEL . . . . . 86

8.4 THE ANALYTIC MODEL . . . . . . . . . . . . . . . . 88

8.5 THE ARCHITECTURE OF THE EXECUTION LEVEL . . . . . . . . . 91

8.6 ENTROPY FORMULATION OF MOTION CONTROL . . . . . . . . 93

8.7 ENTROPY MEASURE OF THE VISION SYSTEM . . . . . . . . . . 95

8.8 ENTROPY MEASURE FOR THE SENSORY SYSTEM . . . . . . . 96

8.9 TOTAL ENTROPY OF THE SYSTEM . . . . . . . . . . . . 96

8.10 REMARKS ......................... 97

8.11 REFERENCES ...................... 97

\section{Chapter 9.}

INTELLIGENT MANUFACTURING 
9.3 ARCHITECTURE OF INTELLIGENT SCHEDULING FOR PRODUCTION

9.3.1 Product Scheduling Architecture: The

Organization Level

9.3.2 Product Scheduling Architecture: The Coordination Level

9.3.3 Product Scheduling Architecture: The

Execution Level

9.4 A PARADIGM OF AUTOMATED PRODUCTION SCHEDULING 112

9.4.1 The Organization Level Structure 114

9.4.2 The Coordination Level Structure 114

9.4.3 The Execution Level Structure 116

9.5 SIMULATION RESULTS FOR THE ASSEMBLY OF A MACHINE 116 9.6 REMARKS

9.7 REFERENCES

Chapter 10.

CONCLUSIONS

10.1 DISTRIBUTED INTELLIGENT MACHINES AND COOPERATING ROBOTS

10.2 FUTURE RESEARCH . . . . . . . . . . . . . . 120

10.3 CONCLUDING REMARKS $\ldots \ldots \ldots \ldots \ldots \ldots \ldots \ldots \ldots \ldots$

10.4. REFERENCES 122 


\section{TABLE OF FIGURES}

Fig. 1.1 Definition of the Intelligent Control Discipline . . . . . . . 2

Fig. 1.2 Man-Machine Interactive Remote Controlled Manipulator . . . 7

Fig. 1.3 NASA Shuttle Mechanical Arm . . . . . . . . . . . . . 8

Fig. 1.4 Block Diagram of SRl's Robot System "Shaky", . . . . . . . . . 9

Fig. 1.5 SRl's Robot System "Shaky" . . . . . . . . . . . . . . 10

FIG. 2.1 Artificial Intelligence vs. Machine Intelligence $\ldots \ldots \ldots \ldots 15$

Fig. 2.2 Flows of Artificial and Machine Intelligence $\ldots \ldots \ldots \ldots \ldots$

Fig. 2.3 The Structure of Intelligent Machines ........... 22

Fig. 4.1 A Hierarchically Intelligent Control System . . . . . . . . . . 39

Fig. 4.2 Topology of the Coordination Level . . . . . . . . . . 43

Fig. 5.1 Typical Architecture of the Organization Level . . . . . . . . 46

Fig. 5.2 The Boltzmann Machine for the Organization Level . . . . . . 51

Fig. 5.3 Modified Genetic Algorithm: The Worst Case . . . . . . . . 56

Fig. 5.4 Modified Genetic Algorithm: The Best Case . . . . . . . . 56

Fig. 5.5 Simulated Annealing: The Worst Case . . . . . . . . . . 57

Fig. 5.6 Simulated Annealing: The Best Case ............. 57

Fig. 5.7 Expanding Subinterval Random Search Algorithm: The Worst

Case ......................... 58

Fig. 5.8 Expanding Subinterval Random Search Algorithm: The Best

Case ............................. 58

Fig. 6.1 The Architecture of the Coordination Level ......... 62

Fig. 6.2 Uniform Design of the Dispatcher and Coordinators . . . . . 64

Fig. 6.3 Architecture of Intelligent Coordination . . . . . . . . . . 65

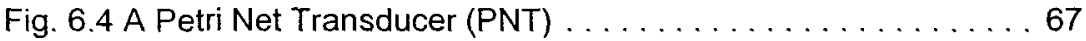

Fig. 6.5 Entropy Measures of a Petri Net Transducer . . . . . . . . 68

Fig. 6.6 Petri Net Diagram of a Typical Coordination Level . . . . . . . 69

Fig. 6.7 A Typical Coordination Structure . . . . . . . . . . . 70

Fig. 6.8 The Language Translation Process . . . . . . . . . 72

Fig. 6.9 Translation Entropies of the Dispatcher and Coordinators . . 74

Fig. 6.10 The Learning Curves of Transitions in the Dispatcher . . . . 75

Fig. 8.1 Hierarchically Intelligent Control of Manipulators with Sensory

Feedback as Developed at the CIRRSE Laboratory of the

Rensselaer Poly. Institute

Fig. 8.2 Hierarchically Intelligent Control of Manipulators with Sensory

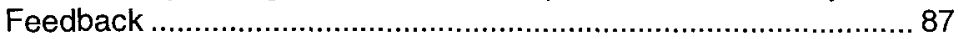

Fig. 8.3 Telerobotics Testbed Configuration Coordination Level ... . . 90

Fig. 8.4 A Case Study of Robotic Truss Assembly ... . . . . . . . 92

Fig. 8.5 The CIRSSE Laboratory for Intelligent Robotic Machines for

Space Construction ......................98 98

Fig. 9.1 A Complete Hierarchically Intelligent Control System . . . . . 102

Fig. 9.2 A Circular Design Robotic Assembly Station . . . . . . . . . 103 
Fig. 9.3 A Linear Design Robotic Assembly Station . . . . . . . . . . 104 Fig. 9.4 Boltzmann Machine Representation for Product Scheduling - 107 Fig. 9.5 A Finite State Machine Generator . . . . . . . . . . . . 109 Fig. 9.6 Alternative Assembly Schedules . . . . . . . . . . 113 Fig. 9.7 The Manufacturing Network . . . . . . . . . . . 115

Fig. 9.8 Learning Curves for Assembly Scheduling . . . . . . . . 118

Fig. 10.1 A View of the New Intelligent Architecture for Robotic Assembly .......................... 121 


\section{TABLE}

Table 2.1 Equivalence of Knowledge Representaiton Techniques . . . . . . . . ..19 
This page is intentionally left blank 


\section{PREFACE}

The Theory of Hierarchically Intelligent Machines originated some forty five years ago when, as a new graduate of the Athens Polytechnic, I was asked to design a "electric shaft" to raise an overflow door of a dam in Greece. The door had two motors at either end and needed to be connected for synchronization. The answer was to install two "synchroes" or synchronous three phase machines with connected rotors. This project introduced me to the concepts of Control Engineering to which I devoted the rest of my career. Intelligent Control came into the picture in 1971, when K. S. Fu coined the name for the area beyond Adaptive and Learning Control which was fashionable at that time. Its theory took shape after long discussions with Norm Caplan at our office at NSF in 1973. Intelligent Machines came later into the picture when I tried to integrate the areas of application of Intelligent Controls.

From the first years of my control experience I tried to venture into more areas more advanced in intelligence, like Adaptive and Learning Control, which were taboo in the sixties. Work in System Identification, Parameter and Performance Adaptive algorithms led into the area of Self-Organizing Control which was also the title of my first book. The idea was to collect all the methods that would provide the ground of utilizing the control experience in areas inside and outside of engineering with minimal interaction with human operators. Intelligent Control was the natural extension of this effort. Robotic systems, especially with applications to Space exploration, where it was needed, was a parallel effort in order to establish the validity of the theory. Within the limits of this work I organized the IEEE Robotics and Automation Society, the Intelligent Control Committee of the Control Systems Society, and several IFAC, Control and Robotics Conferences and Symposia. As a generalization of this effort was the extension of the theory to Intelligent Machines, with major applications to prosthetic devices, and Intelligent Manufacturing. In the meanwhile Entropy came into the picture as an integrating measure among the various engineering and non-engineering fields and an appropriate theory was developed.

I then established a pioneering, NASA supported Center for Intelligent Robotic Systems for Space Exploration, CIRSSE, at RPI, with ten professors and fifty students, and a one and a half million dollar laboratory facility. The center, in its five year existence, produced a large number of papers, technical reports and especially remote space truss assembly from the NASA Space Center at Houston, without the interference of a human operator. An Intelligent Manufacturing application for product scheduling was also performed by a student in Greece, to show the generality of the theory of Intelligent Machines. 
-xvi-

This book summarizes the Theory of Intelligent Machines, and should be used to explore its capability to apply to engineering as well as various soft sciences, like biotechnology, ecology, pollution control and waste management, evolutionary biology, economics, etc. It is hoped that young researchers as well as professionals will pick up the flag and carry the whole Theory and Applications to new frontiers. At this point I want to thank all my students and colleagues who have contributed to the development of the material presented in this volume and especially my wife Youla whose patience and understanding made this book possible.

George N. Saridis PhD Loudonville NY

February 2001 